\title{
STUDI PELAKSANAAN SERTA HASIL BELAJAR FISIKA PADA UJIAN TENGAH SEMESTER TAHUN 2012 - 2013 DI SEKOLAH MENENGAH ATAS (SMA)
}

\author{
Leny Khairani Daulay dan Alkhafi Maas Siregar \\ Jurusan Fisika FMIPA Universitas Negeri Medan \\ Leny.khairani.589@gmail.com
}

\begin{abstract}
ABSTRAK
Penelitian ini dilakukan untuk mengetahui besar pelaksanaan penilaian pendidikan yang sesuai standar nasional pendidikan (SNP) guna memetakan kemampuan guru dalam menilai dan prosedur dari penilaian ujian tengah semester yang telah ditetapkan oleh badan standar nasional pendidikan (BSNP) terutama pada hasil belajar fisika pada ujian tengah. Jenis penelitian ini adalah kualitatif. Penentuan sampel sumber data dilakukan dengan teknik purposif sampling yaitu beberapa guru fisika dan beberapa siswa di sekolah menengah atas (SMA) dengan pertimbangan akreditas sekolah A,B, C, identitas guru, dan sertifikasi dengan cara melakukan penyebaran angket, wawancara, dokumentasi, dan memberikan soal kepada siswa. Teknik analisis data dalam penelitian ini yaitu reduksi data, display data, dan kesimpulan/verifikasi. Hasil penelitian menunjukkan bahwa prosedur pelaksanaan penilaian ujian tengah semester yang dilakukan guru di kelas sebesar 44,80\%, ini merupakan sebuah proses triangulasi yang peneliti lakukan untuk mendapatkan keakuratan pelaksanaan penilaian guru pada ujian tengah semester disetiap sekolah. Hal ini terjadi karena kurangnya pemahaman guru dalam melakukan standar penilaian sesuai badan standar nasional pendidikan (BSNP) dan kurangnya sosialisasi dan pembinaan dari pemerintah, serta tidak adanya pernyamaan persepsi yang dilakukan oleh dinas pendidikan setempat sehingga guru melakukan penilaian yang menurut guru pahami. Hasil tes ujian tengah semester fisika sangat kurang dengan nilai rata-rata test ujian tengah semester hanya sebesar $25,53 \%$. Ini terjadi karena minat dan motivasi peserta didik dalam mengikuti mata pelajaran fisika serta hasil test yang diberikan masih sangat rendah, dan kurangnya kemampuan guru mencari metode yang dapat membuat peserta didik menjadi lebih senang dalam mengikuti pelajaran, terutama bagi peserta didik yang sering mengalami kondisi membosankan.
\end{abstract}

Kata Kunci: purposif sampling, pelaksanaan penilaian, ujian tengah semester.

\section{PENDAHULUAN}

Dalam Pasal 1 ayat (17) Undang-undang nomor 20 tahun 2003 tentang Sistem Pendidikan Nasional yang tertuang dalam Pasal 2 Ayat (1) PP No.19 tahun 2005 dinyatakan bahwa lingkup dari Standar Nasional Pendidikan meliputi 8 standar yaitu: (1) standar isi, (2) standar proses, (3) standar kompetensi lulusan, (4) standar pendidik dan tenaga kependidikan, 
(5) standar sarana dan prasarana, (6) standar pengelolaan, (7) standar pembiayaan, dan (8) standar penilaian pendidikan. Standar penilaian pendidikan adalah standar nasional pendidikan yang berkaitan dengan mekanisme, prosedur, dan instrumen penilaian hasil belajar peserta didik. Pada lampiran bagian mekanisme dan prosedur, dinyatakan bahwa penilaian pendidikan pada jenjang pendidikan dasar dan menengah dilakukan oleh pendidik, satuan pendidikan dan pemerintah. (Permendiknas No.20 Tahun 2007). Kurikulum tingkat satuan pendidikan (KTSP) merupakan kurikulum operasional yang disusun dan dilaksanakan oleh masingmasing satuan pendidikan dengan mengacu pada standar nasional pendidikan yang disusun oleh Badan Standar Nasional Pendidikan (BSNP). KTSP terutama berkaitan dengan Standar Isi dan Standar Kompetensi Lulusan (SKL). Pengembangan KTSP yang beragam mengacu pada standar nasional pendidikan untuk menjamin pencapaian tujuan pendidikan nasional (BSNP, 2005).

\section{Tujuan penilaian adalah} untuk mengetahui tingkat pencapaian kompetensi yang diperoleh peserta didik, sebagai bahan penyusunan laporan kemajuan hasil belajar,dan memperbaiki proses pembelajaran berdasarkan Kurikulum yang berlaku. Penilaian diperoleh melalui teknik tes maupun non-tes dari berbagai perangkat ukur maupun bentuk lainya (tes tertulis, lisan, atau kinerja) dan dilakukan secara konsisten, sistematis dan terprogram. Dalam penilaian selalu mengandung proses. Proses penilaian harus tepat terhadap tipe tujuan pembelajaran. Dikarenakan tidak semua tujuan pembelajaran dapat dinyatakan dengan alat penilaian yang sama, maka penilaian menjadi salah satu hal yang sulit dan menantang, yang harus disadari oleh para guru.

Febriyanti (2012) dengan judul "Penerapan Metode Multivariate Adaptive Regression Spline (Mars) Untuk Mengidentifikasi Komponen Yang Berpengaruh Terhadap Peringkat Akreditasi Sekolah" menyimpulkan bahwa dari delapan variabel prediktor yang diteliti pada penelitian ini, terdapat tujuh variabel prediktor yang berkontribusi terhadap model MARS, yaitu komponen standar sarana dan prasarana, komponen standar kompetensi lulusan, komponen standar penilaian, komponen standar isi, komponen standar pembiayaan, komponen standar proses, komponen standar pengelolaan dengan tingkat kepentingan berturut-turut 100\%, $83.93 \%, \quad 56.27 \%, \quad 54.27 \%, \quad 45.86 \%$, $23.35 \%, 22.67 \%$ dan satu variabel yaitu komponen standar pendidik dan tenaga didik yang tidak berpengaruh dalam pengklasikasian.

Penelitian tentang penilaian sebelumnya telah dilakukan oleh Pasaribu (2012) yang meneliti pemahaman guru fisika tentang penilaian di beberapa sekolah dan menemukan secara umum bahwa, penilaian yang dilakukan guru fisika di beberapa Sekolah Menengah Atas (SMA) yang ada di Medan masih kurang sesuai dengan tuntutan KTSP. Di sisi lain, masih banyak guru fisika yang belum mengetahui isi dari Permendiknas 
No. 20 tahun 2007 ini. Mekanisme dan teknik penilaian yang dilakukan oleh guru belum mengikuti standar yang telah ditetapkan oleh Badan Standar Nasional Pendidikan, dan masih cenderung menggunakan penilaian tradisional. Bahkan guru fisika jarang menggunakan lebih dari dua teknik penilaian. Diperkuat oleh hasil penelitian Kurniawan (2013) menjelaskan bahwa penilaian yang dilakukan guru fisika belum dilakukan secara komprehensif dan hanya sebesar $27 \%$ dari total sampel sumber data guru fisika yang memvariasikan bentuk dan teknik penilaiannya dan yang lain hanya melakukan penilaian pada ujian akhir semester.

Berdasarkan uraian di atas peneliti tertarik untuk mempelajari penilaian yang dilakukan guru fisika di beberapa sekolah di Medan. Fokus penelitian adalah pelaksanaan penilaian pada ujian tengah semester dari tahun 2012 2013. Penelitian ini penting karena ujian tengah semester (UTS) ditujukan untuk menentukan keberhasilan peserta didik yang diwujudkan dalam pemberian nilai, termasuk untuk bahan pertimbangan kenaikan kelas.

\section{METODE PENELITIAN}

Metode yang digunakan dalam penelitian ini adalah metode kualitatif, dan jenis penelitiannya adalah penelitian survei deskriftif. Peneliti menggunakan metode kualitatif karena permasalahan belum fokus, holistik, kompleks, dinamis, dan penuh makna. Sampel sumber data dipilih secara purposive, dalam penelitian ini, sampel sumber datanya adalah guru fisika SMA dengan pertimbangan, kualifikasi guru, golongan, umur, sertifikasi, dan lama mengajar serta siswa. Dalam penelitian ini, teknik pengumpulan data yang digunakan adalah kuesioner, wawancara mendalam, dan dokumen. Kuesioner, dan wawancara mendalam akan dilakukan kepada guru fisika dari beberapa sekolah yang memiliki akreditasi yang berbeda serta membagikan soal UTS kepada para siswa.

Jenis kuesioner yang digunakan adalah kuesioner tak berstruktur. Kuesioner tak berstruktur digunakan untuk menggali informasi yang diinginkan dan sumber data dapat memberikan informasi dengan bebas. Setelah peneliti mendapatkan fokus atau inti permasalahan yang akan diteliti, maka peneliti akan melakukan wawancara yang mendalam kepada sampel sumber data.

\section{HASIL DAN PEMBAHASAN}

Profil responden yang diamati dalam penelitian ini adalah latar belakang pendidikan, status kepegawaian, dan pengalaman mengajar.

Tabel 1. Profil Sampel Sumber Data Sekolah dan Guru Fisika SMA

\begin{tabular}{|c|c|c|c|c|c|}
\hline No. & \multicolumn{4}{|c|}{ Uraian } & Sumber \\
\hline \multirow{5}{*}{1} & $\begin{array}{l}\text { Akredita } \\
\text { Sekolah }\end{array}$ & $\begin{array}{l}\text { Seko } \\
\text { lah } 1\end{array}$ & $\begin{array}{l}\text { Seko } \\
\text { lah } 2\end{array}$ & $\begin{array}{c}\text { Sekola } \\
\text { h } 3 \\
\end{array}$ & \multirow{4}{*}{$\begin{array}{l}\text { Data } \\
\text { Dinas } \\
\text { Pendidi } \\
\text { kan }\end{array}$} \\
\hline & A & $\sqrt{ }$ & & & \\
\hline & B & & $\sqrt{ }$ & & \\
\hline & $\mathrm{C}$ & & & $\sqrt{ }$ & \\
\hline & Status & $\begin{array}{l}\text { Nege } \\
\text { ri }\end{array}$ & $\begin{array}{l}\text { Nege } \\
\text { ri }\end{array}$ & $\begin{array}{l}\text { Swast } \\
\text { a }\end{array}$ & \\
\hline \multirow{4}{*}{2} & $\begin{array}{c}\text { Identita } \\
\text { s Guru }\end{array}$ & & & & \multirow{4}{*}{$\begin{array}{l}\text { Wawan } \\
\text { cara }\end{array}$} \\
\hline & S-3 & & & & \\
\hline & S-2 & & & & \\
\hline & S-1 & $\sqrt{ }$ & $\sqrt{ }$ & & \\
\hline
\end{tabular}




\begin{tabular}{|c|c|c|c|c|}
\hline & $\begin{array}{c}\text { Non- } \\
\text { gelar }\end{array}$ & & $\sqrt{ }$ \\
\cline { 2 - 4 } & $\begin{array}{c}\text { Sertifik } \\
\text { asi }\end{array}$ & $\sqrt{ }$ & $\sqrt{ }$ & \\
\hline $\begin{array}{c}\text { Belum } \\
\text { sertifik } \\
\text { asi }\end{array}$ & & $\sqrt{ }$ & \\
\cline { 1 - 4 } & $\begin{array}{c}\text { Pengala } \\
\text { man } \\
\text { Mengaj } \\
\text { ar }\end{array}$ & 26 & 20 & 29 \\
Thn & Thn & Thn & \\
\hline
\end{tabular}

Adapun hasil yang diperoleh dari data penelitian dengan menggunakan angket siswa SMA tentang indikator pemahaman guru fisika SMA terhadap pelaksaanaan penilaian ujian tengah semester, guru bidang studi fisika SMA dan hasil belajar siswa pada mata pelajaran fisika saat ujian tengah semester adalah sebagai berikut:

\section{Angket Siswa}

Tabel 2. Hasil Angket Siswa tentang Kemampuan Guru Dalam Melakukan Penilaian Ujian Tengah Semester

\begin{tabular}{|c|c|c|c|c|c|}
\hline No & $\begin{array}{c}\text { Aspek } \\
\text { Yang } \\
\text { Dinilai }\end{array}$ & $\begin{array}{l}\text { Sekola } \\
\text { h- } 1\end{array}$ & $\begin{array}{l}\text { Seko } \\
\text { lah-2 }\end{array}$ & $\begin{array}{l}\text { Seko } \\
\text { lah-3 }\end{array}$ & $\begin{array}{l}\text { Rata - } \\
\text { rata tiap } \\
\text { Aspek }\end{array}$ \\
\hline 1. & Aspek 1 & $73,3 \%$ & $65,0 \%$ & $55,0 \%$ & $64,43 \%$ \\
\hline 2. & Aspek 2 & $65,0 \%$ & $50,0 \%$ & $40,0 \%$ & $51,67 \%$ \\
\hline 3. & Aspek 3 & $76,6 \%$ & $60,0 \%$ & $60,0 \%$ & $65,53 \%$ \\
\hline 4. & Aspek 4 & $50,0 \%$ & $40,0 \%$ & $35,0 \%$ & $41,66 \%$ \\
\hline 5. & Aspek 5 & $60,0 \%$ & $45,0 \%$ & $40,0 \%$ & $48,33 \%$ \\
\hline 6. & Aspek 6 & $80,0 \%$ & $50,0 \%$ & $45,0 \%$ & $58,33 \%$ \\
\hline 7. & Aspek 7 & $65.0 \%$ & $55,0 \%$ & $50,0 \%$ & $56,66 \%$ \\
\hline 8. & Aspek 8 & $100 \%$ & $92,9 \%$ & $92,9 \%$ & $95,26 \%$ \\
\hline 9. & Aspek 9 & $55,0 \%$ & $55,0 \%$ & $45,0 \%$ & $51,66 \%$ \\
\hline 10. & Aspek 10 & $60,0 \%$ & $55,0 \%$ & $45,0 \%$ & $53,33 \%$ \\
\hline 11. & Aspek 11 & $40,0 \%$ & $80,0 \%$ & $80,0 \%$ & $66,66 \%$ \\
\hline 12. & Aspek 12 & $60,0 \%$ & $46,7 \%$ & $40,0 \%$ & $48,90 \%$ \\
\hline \multicolumn{2}{|c|}{$\begin{array}{c}\text { Rata - rata } \\
\text { tiap } \\
\text { sekolah }\end{array}$} & $65,41 \%$ & $57,88 \%$ & $53,15 \%$ & $62,91 \%$ \\
\hline
\end{tabular}

\section{Keterangan}

1. Aspek 1: Guru memberikan soal yang sudah dipelajari untuk ujian

2. Aspek 2: Cara penilaian UTS diberitahu jauh hari sebelum UTS oleh guru.
3. Aspek 3: Guru menilai hasil ujian tengah semester dan mengembalikan kepada siswa

4. Aspek 4: Guru melakukan remedial bagi yang hasil UTS nya tidak mencapai KKM.

5. Aspek 5: Remedial dilaksanakan pada jam belajar efektif.

6. Aspek 6: Dalam kegiatan ujian tengah semester, guru memberikan arahan dan aturan untuk perilaku disiplin.

7. Aspek 7: Dalam kegiatan ujian tengah semester, bahasa soal yang diberikan guru mudah dipahami.

8. Aspek 8: UTS dilaksanakan dengan Ujian Tertulis.

9. Aspek 9: Dalam kegiatan ujian tengah semester saat menjawab soal, guru memberikan arahan tentang perlunya bersikap ilmiah terutama berlaku jujur, objektif, dan tidak mencontek.

10. Aspek 10: Dalam menilai hasil ujian tengah semester, guru berlaku adil tanpa pilih kasih.

11. Aspek 11: Sebelum ujian tengah semester, guru menyampaikan aspek-aspek yang akan menjadi penilaian dalam ujian fisika selain menjawab soal dengan benar. Misalnya: disiplin, tingkah laku, sikap, dan sebagainya.

12. Aspek 12 : Cara mengajar guru lebih baik setiap UTS selesai dilaksanakan.

Gambar 1. menunjukkan bahwa menurut siswa bahwa kemampuan guru dalam melaksanakan penilaian ujian tengah semester masih rendah, ini dapat dilihat dari hasil rata-rata nilai tiap aspek siswa yang hanya sebesar 62,91\%. Hal ini menunjukkan bahwa secara rata rata siswa merasa guru masih 
kurang mampu melakukan penilaian ujian tengah semester.

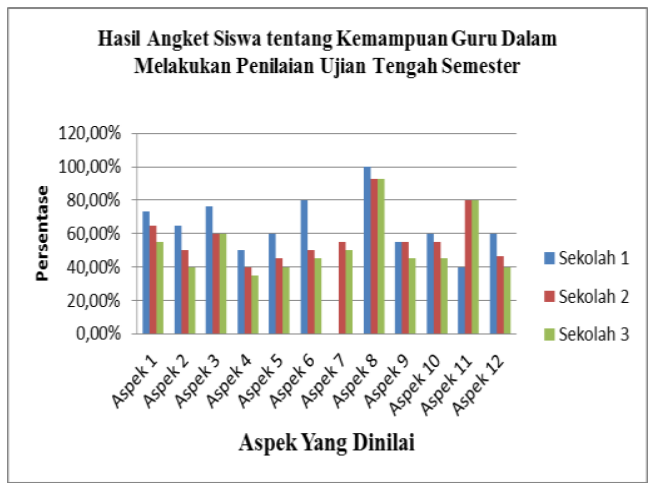

Gambar 1. Grafik siswa tentang kemampuan guru dalam melakukan penilaian ujian tengah semester

\section{Angket Guru Fisika Dalam Melakukan Penilaian}

Tabel 3. Hasil Angket tentang Kemampuan Guru Dalam Melakukan Penilaian Ujian Tengah Semester Berdasarkan Kriteria BSNP

\begin{tabular}{|c|c|c|c|c|c|}
\hline No & $\begin{array}{c}\text { Aspek } \\
\text { Yang } \\
\text { Dinilai }\end{array}$ & Guru-1 & $\begin{array}{c}\text { Guru- } \\
2\end{array}$ & $\begin{array}{c}\text { Guru- } \\
3\end{array}$ & $\begin{array}{c}\text { Rerata } \\
\text { tiap } \\
\text { Aspek }\end{array}$ \\
\hline 1. & Aspek 1 & $100,0 \%$ & $50,0 \%$ & $50,0 \%$ & $67 \%$ \\
\hline 2. & Aspek 2 & $45,0 \%$ & $65,0 \%$ & $65,0 \%$ & $58 \%$ \\
\hline 3. & Aspek 3 & $60,0 \%$ & $66,7 \%$ & $66,7 \%$ & $65 \%$ \\
\hline 4. & Aspek 4 & $57,1 \%$ & $55,0 \%$ & $55,0 \%$ & $58 \%$ \\
\hline 5. & Aspek 5 & $53,3 \%$ & $66,0 \%$ & $60,0 \%$ & $60 \%$ \\
\hline 6. & Aspek 6 & $65,0 \%$ & $50,0 \%$ & $50,0 \%$ & $55 \%$ \\
\hline 7. & Aspek 7 & $50,0 \%$ & $57,1 \%$ & $53,8 \%$ & $54 \%$ \\
\hline 8. & Aspek 8 & $55,0 \%$ & $60,0 \%$ & $60,0 \%$ & $58 \%$ \\
\hline 9. & Aspek 9 & $50,0 \%$ & $80,0 \%$ & $72,9 \%$ & $68 \%$ \\
\hline 10. & Aspek 10 & $66,7 \%$ & $66,7 \%$ & $60,0 \%$ & $65 \%$ \\
\hline 11. & Aspek 11 & $80,0 \%$ & $55,0 \%$ & $50,0 \%$ & $62 \%$ \\
\hline 12. & Aspek 12 & $92,9 \%$ & $80,0 \%$ & $60,0 \%$ & $78 \%$ \\
\hline & Rata - & $64 \%$ & $57 \%$ & $59 \%$ & $61 \%$ \\
& rata tiap & & & & \\
\hline
\end{tabular}

Keterangan :

1. Aspek 1: Ada atau tidak adanya informasi rancangan kriteria penilaian UTS pada silabus, kepada para siswa jauh hari sebelum pelaksanaan UTS dilakukan.
2. Aspek 2: Kesesuaian teknik penilaian UTS pada silabus dengan indikator pencapaian $\mathrm{KD}$ pada periode tersebut.

3. Aspek 3: Kesesuaian instrumen dan pedoman penilaian UTS dengan bentuk dan teknik penilaian.

4. Aspek 4: Berapa persen penilaian hasil Ujian Tengah Semester yang bersifat otentik.

5. Aspek 5: Macam penilaian UTS yang digunakan: traditional (tes tertulis), alternative assessmen.

6. Aspek 6: Macam tes tertulis dalam UTS yang digunakan: essay atau multiple choice.

7. Aspek 7: Tingkat taksonomi Bloom yang digunakan pada tes tertulis dalam UTS.

8. Aspek 8: Berapa macam teknik penilaian UTS yang digunakan.

9. Aspek 9: Ada atau tidak adanya lebih dari satu teknik penilaian UTS.

10. Aspek 10: Ada atau tidak adanya pengolahan hasil penilaian UTS untuk mengetahui kemajuan dan kesulitan belajar.

11. Aspek 11: Ada atau tidak adanya pemanfaatan hasil penilaian UTS untuk perbaikan pembelajaran

12. Aspek 12: Ada atau tidak adanya balikan hasil UTS siswa disertai masukan/komentar yang mendidik. 


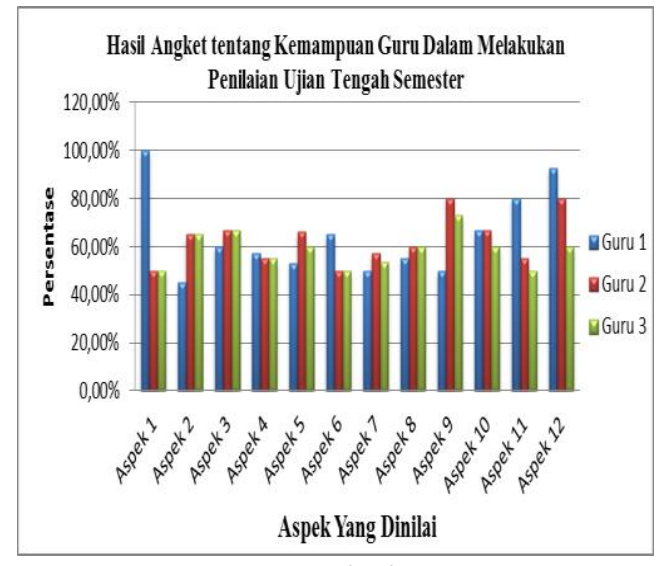

Gambar 2. Grafik kemampuan guru dalam melakukan penilaian ujian tengah semester berdasarkan kriteria BSNP

Gambar 2. menunjukkan bahwa guru belum sepenuhnya melaksanakan penilaian ujian tengah semester yang sesuai standart, ini dapat dilihat dari tabel 4.3. tentang hasil kemampuan guru dalam melakukan penilaian ujian tengah semester yang rata-rata tiap aspek hanya sebesar $61 \%$, hal ini sangat kurang kesempurnaaan dalam pelaksanaan penilaian ujian tengah semester yang dilakukan guru. Pelaksanaan penilaian tengah semester harus sempurna agar pelaksanaan penilaian yang diharapkan sesuai dengan Badan Standar Nasional pendidikan.

\section{Test Ujian Tengah Semester Fisika}

Tabel 4. Hasil Test tentang Kemampuan Siswa Dalam Menyelesaikan Soal Soal Fisika Pada Ujian Tengah Semester

\begin{tabular}{|c|c|c|c|c|c|}
\hline \multirow{2}{*}{ No } & \multirow{2}{*}{ Soal } & \multicolumn{4}{|c|}{$\begin{array}{c}\text { Jumlah Soal Yang Dijawab } \\
\text { Benar }\end{array}$} \\
\cline { 3 - 6 } & & $\begin{array}{c}\text { Sekol } \\
\text { ah-1 }\end{array}$ & $\begin{array}{c}\text { Sekol } \\
\text { ah-2 }\end{array}$ & $\begin{array}{c}\text { Sekol } \\
\text { ah-3 }\end{array}$ & $\begin{array}{c}\text { Rata - } \\
\text { rata } \\
\text { tiap } \\
\text { soal }\end{array}$ \\
\hline 1. & Soal 1 & $37 \%$ & $32 \%$ & $30 \%$ & $32 \%$ \\
\hline 2. & Soal 2 & $27 \%$ & $31 \%$ & $25 \%$ & $27,7 \%$ \\
\hline 3. & Soal 3 & $25 \%$ & $27 \%$ & $23 \%$ & $25 \%$ \\
\hline 4. & Soal 4 & $52 \%$ & $55 \%$ & $45 \%$ & $50,6 \%$ \\
\hline 5. & Soal 5 & $15 \%$ & $10 \%$ & $8 \%$ & $11 \%$ \\
\hline 6. & Soal 6 & $40 \%$ & $34 \%$ & $30 \%$ & $34,6 \%$ \\
\hline 7. & Soal 7 & $23 \%$ & $23 \%$ & $21 \%$ & $23 \%$ \\
\hline 8. & Soal 8 & $31 \%$ & $30 \%$ & $28 \%$ & $29,6 \%$ \\
\hline 9. & Soal 9 & $10 \%$ & $10 \%$ & $7 \%$ & $9 \%$ \\
\hline 10. & Soal 10 & $25 \%$ & $6 \%$ & $7 \%$ & $12,6 \%$ \\
\hline $\begin{array}{c}\text { Rata } \\
\text { tiap sekolah }\end{array}$ & $\begin{array}{c}28,4 \\
\%\end{array}$ & $\begin{array}{c}25,8 \\
\%\end{array}$ & 22,4 & $25,51 \%$ \\
$\%$ & \\
\hline
\end{tabular}

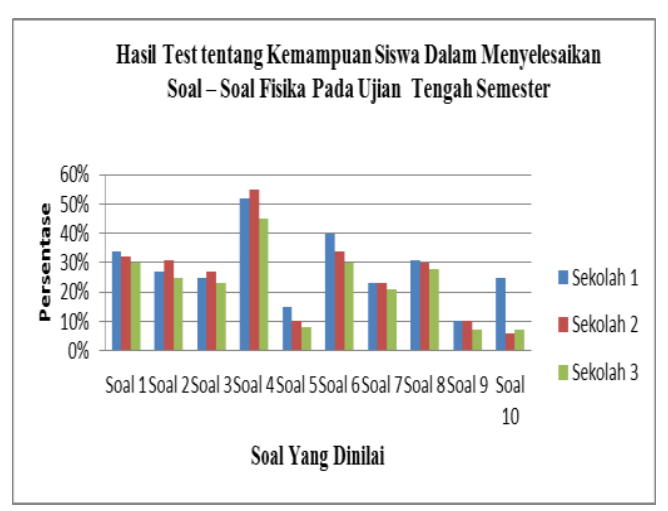

Gambar 3. Grafik hasil tes kemampuan siswa dalam menyelesaikan soal - soal fisika pada ujian tengah semester

Dari hasil test yang didapat di setiap sekolah bahwa kurangnya kemampuan siswa dalam mengerjakan test yang diberikan, hal ini ditunjukkan dari tabel 4 . yaitu hasil test tentang kemampuan siswa dalam menyelesaikan soalsoal fisika dari rata - rata nilai tiap aspek soal yang hanya sebesar $25,51 \%$. Ini sangat kurang dari 
standart yang telah ditentukan, $\mathrm{Hal}$ ini menjadi temuan besar yang seharusnya cepat ditindak lanjuti sehingga diharapkan memberikan kontribusi baik bagi sekolah, guru serta harus dirubah siswa.

\section{SIMPULAN}

Berdasarkan hasil penelitian yang diperoleh maka dapat disimpulkan: (1) Kemampuan siswa dalam menyelesaikan soal - soal ujian tengah semester yang sesuai KTSP melalui test yang diperoleh di setiap sekolah masih rendah, dilihat berdasarkan test yang diberikan kepada siswa diperoleh nilai rata rata dari sekolah yang berakreditas A sebesar 28,4\%, sekolah yang berakreditas B sebesar 25,8\%, sekolah yang berakreditas $\mathrm{C}$ sebesar $22,4 \%$, dan rendahnya kemampuan siswa dalam menyelesaikan soal soal ujian tengah semester disebabkan karena cara mengajar guru disetiap sekolah berbeda beda, kurangnya pemahaman guru terkait model-model pembelajaran yang berbasis pada kompetensi siswa, sehingga peserta didik merasa jenuh dan bosan dengan pelajaran yang diberikan, buku yang digunakan disetiap sekolah berbeda - beda, dan kurikulum tingkat satuan pendidikan (KTSP) disetiap sekolah juga berbeda - beda. (2) Soal - soal fisika yang digunakan guru pada ujian tengah semester belum sesuai dengan tuntutan KTSP yang digunakan dikarenakan faktor dari internal guru seperti dalam membuat soal guru tidak menggunakan kisi - kisi soal (tiga indeks tingkat kesukaran) yaitu sukar, sedang, dan mudah, guru tidak menggunakan pengecoh pengecoh yang efektif, dan guru tidak mereview kembali apakah soal tersebut telah memenuhi syarat penulisan soal yang baik.

Kemampuan guru dalam melakukan penilaian ujian tengah semester yang sesuai dengan Badan Standar Nasional Pendidikan (BSNP) pada sekolah yang berakreditas A sudah bagus pada Aspek 1: Ada atau tidak adanya informasi rancangan kriteria penilaian UTS pada silabus, kepada para siswa jauh hari sebelum pelaksanaan UTS dilakukan. Aspek 9: Ada atau tidak adanya pemanfaatan hasil penilaian UTS untuk perbaikan pembelajaran, dan Aspek 10: Ada atau tidak adanya balikan hasil UTS siswa disertai masukan/komentar yang mendidik. Sedangkan pada aspek 2: Kesesuaian teknik penilaian UTS pada silabus dengan indikator pencapaian KD pada periode tersebut., aspek 3: Kesesuaian instrumen dan pedoman penilaian UTS dengan bentuk dan teknik penilaian, aspek 4: Berapa persen penilaian hasil Ujian Tengah Semester yang bersifat otentik, aspek 5: Macam penilaian UTS yang digunakan: traditional (tes tertulis), alternative assessmen, aspek 6: berapa macam teknik penilaian UTS yang digunakan, aspek 7: ada atau tidak adanya lebih dari satu teknik penilaian UTS, dan aspek 8: ada atau tidak adanya pengolahan hasil penilaian UTS untuk mengetahui kemajuan dan kesulitan belajar masih rendah. Pada sekolah yang berakreditas B yang sudah bagus hanya pada aspek 7 dan aspek 10 , sedangkan pada aspek 1, 2, 3, 4, 5,6, 8, dan aspek 9 masih rendah. Pada sekolah yang berakreditas $\mathrm{C}$ yang bagus hanya pada aspek 7, sedangkan pada aspek $1,2,3,4,5$, $6,8,9$, dan 10 masih rendah. Dilihat berdasarkan angket guru tentang 
penilaian ujian tengah disebabkan karena penilaian yang dilakukan guru masih cenderung menggunakan penilaian tradisional, jarang menggunakan lebih dari dua teknik penilaian dalam ujian tengah semester, penilaian yang dilakukan hanya mencakup aspek pengetahuan peserta didik, guru tidak mempunyai format penilaian afektif dan psikomotorik yang benar, hanya melihat dari keseharian siswa dalam proses belajar mengajar. (4) Kendala guru dalam melakukan penilaian ujian tengah semester yang berstandar BSNP disetiap sekolah dikarenakan beberapa faktor baik dari internal guru seperti kurang sosialisasi dan pembinaan dari pemerintah, serta tidak adanya pernyamaan persepsi yang dilakukan oleh dinas pendidikan setempat sehingga guru melakukan penilaian ujian tengah semester yang menurut guru pahami. Kendala dari tempat mereka mengajar yaitu sekolah seperti sistem yang mereka terapkan disetiap sekolah sudah dari dahulu seperti itu adanya, sehingga tidak ada improvisasi informasi yang berkembang.

\section{SARAN}

Saran yang dapat peneliti ajukan berdasarkan pembahasan adalah sebagai berikut: (1) Perlunya perlengkapan administrasi seperti surat menyurat dan jurnal penelitian untuk mendukung penelitian. (2) Perlunya kelengkapan data tentang penilaian guru pada ujian tengah semester dari wakil kepala sekolah (bagian kurikulum) agar data yang didapat lebih valid. (3) Perlunya sampel sumber data yang lebih banyak agar penelitian selanjutnya mendapatkan hasil yang bervariasi dan lebih baik.

\section{DAFTAR PUSTAKA}

Febriyanti, A., Yozza, H., dan Rahmi,I., (2012), Penerapan Metode Multivariate Adaptive Regression Spline (Mars) Untuk Mengidentifikasi Komponen Yang Berpengaruh Terhadap Peringkat Akreditasi Sekolah, Jurnal Matematika UNAND 2: 2303-2910

Haryati, M., (2007), Model dan Teknik Penilaian Pada Tingkat Satuan Pendidikan, Gaung Persada Press, Jakarta

Kurniawan, C., (2013), Pemahaman

Guru Fisika Se-Kota Madya

Medan Dalam

Mengimplementasikan Standar Evaluasi Pendidikan. Skripsi, FMIPA, UNIMED, Medan

Mulyasa, H., E., (2009), Implementasi Kurikulum Tingkat Satuan Pendidikan, P.T Bumi Aksara, Jakarta

Pasaribu, V., R., (2012), Studi Implementasi Guru dalam Melaksanakan Standar Penilaian Pendidikan di Sekolah Menengah Atas seKota Medan. Skripsi, FMIPA, UNIMED, Medan

Sukardi, (2003), Metodologi Penelitian Pendidikan, Bumi Aksara, Jakarta

Sukmadinata, N., S., (2005), Metode Penelitian Pendidikan, P.T Remaja Rosdakarya, Bandung

Sugiyono, (2010), Metode Penelitian Pendidikan (Pendekatan Kuantitatif, Kualitatif, dan R\&D), Alfabeta, Bandung Permendiknas

Nomor 20 Tahun 2007 tentang Standar Penilaian Pendidikan 